University of Nebraska - Lincoln

DigitalCommons@University of Nebraska - Lincoln

$7-2003$

\title{
Assessing the Wraparound Process During Family Planning Meetings
}

\author{
Michael Epstein \\ University of Nebraska - Lincoln, mepstein1@unl.edu \\ Philip D. Nordness \\ University of Nebraska - Lincoln \\ Krista Kutash \\ University of South Florida \\ Al Duchnowski \\ University of South Florida \\ Sheryl Schrepf \\ Families, First, and Foremost, Lincoln, Nebraska \\ See next page for additional authors
}

Follow this and additional works at: https://digitalcommons.unl.edu/specedfacpub

Part of the Special Education and Teaching Commons

Epstein, Michael; Nordness, Philip D.; Kutash, Krista; Duchnowski, Al; Schrepf, Sheryl; Brenner, Greg J.; and Nelson, J. Ron, "Assessing the Wraparound Process During Family Planning Meetings" (2003). Special Education and Communication Disorders Faculty Publications. 56.

https://digitalcommons.unl.edu/specedfacpub/56

This Article is brought to you for free and open access by the Department of Special Education and Communication Disorders at DigitalCommons@University of Nebraska - Lincoln. It has been accepted for inclusion in Special Education and Communication Disorders Faculty Publications by an authorized administrator of DigitalCommons@University of Nebraska - Lincoln. 


\section{Authors}

Michael Epstein, Philip D. Nordness, Krista Kutash, Al Duchnowski, Sheryl Schrepf, Greg J. Brenner, and J. Ron Nelson 
Published in Journal of Behavioral Health Services \& Research 30:3 (July-September 2003), pp. 352-362. Copyright $\odot 2003$ National Council for Community Behavioral Healthcare; published by Springer

Verlag. Used by permission.

\title{
Assessing the Wraparound Process During Family Planning Meetings
}

\author{
Michael H. Epstein, EdD \\ Philip D. Nordness, MA \\ Krista Kutash, $\mathrm{PhD}$ \\ Al Duchnowski, PhD \\ Sheryl Schrepf, MSW \\ Greg J. Benner, MEd \\ J. Ron Nelson, PhD
}

\begin{abstract}
Research and evaluation of the wraparound process has typically focused on outcomes, service providers, and costs. While many of these studies describe a process that is consistent with the wraparound approach, few studies have reported attempts to monitor or measure the treatment fidelity of the wraparound process. The purpose of this study was to assess the fidelity of the wraparound process in a community-based system of care using the Wraparound Observation Form-Second Version. Results from 112 family planning meetings indicated some strengths and weaknesses within the current system. Families and professionals were frequently involved in the planning and implementation of the wraparound process. However, informal supports and natural family supports were not present in a majority of the meetings. Given the significant number of youth served in wraparound programs, the benefits of using the Wraparound Observation Form-Second Version as an instrument to monitor the fidelity of the wraparound approach should not be ignored.
\end{abstract}

According to the Surgeon General's ${ }^{1}$ report on the mental health of children, as many as $13 \%$ of children in the United States have serious emotional disturbance (SED). Children with SED often experience a number of mental health problems that significantly impair their abil-

Corresponding author - Michael H. Epstein, EdD, William Barkley Professor of Special Education, Co-Director, Center for At-Risk Children's Services, Department of Special Education and Communication Disorders, University of Nebraska-Lincoln, 202 Barkley Memorial Center, PO Box 837032, Lincoln, NE 68583-7032; Email mepstein1@unl.edu

Philip D. Nordness, MA, is a doctoral Candidate in Special Education at University of Nebraska-Lincoln.

Krista Kutash, PhD, is Deputy Director of Research and Training Center for Children's Mental Health in Department of Child and Family Studies in Louise de la Parte Institute at University of South Florida, Tampa, Florida.

Al Duchnowski, PhD, is Deputy Director of Research and Training Center for Children's Mental Health in Department of Child and Family Studies in Louise de la Parte Institute at University of South Florida, Tampa, Florida.

Sheryl Schrepf, MSW, is Executive Director of Families, First, and Foremost, Lincoln, Nebraska.

Greg J. Benner, MEd, is a doctoral candidate in Special Education at University of Nebraska-Lincoln.

J. Ron Nelson, PhD, is Associate Research Professor of Special Education and Co-Director of Center for At-Risk Children's Services at University of Nebraska-Lincoln. 
ity to function socially, academically, and emotionally across a variety of life domains. To help meet the needs of children and their families, the mental health system spent almost \$12 billion supplying behavioral health care for children and youth in $1998 .^{2}$

During the last 2 decades there have been significant efforts to improve the services delivery system for children with SED. ${ }^{3}$ These initiatives have been marked by a shift from categorical to integrated service systems, ${ }^{4}$ from institutional to community-based services, ${ }^{5}$ and, most recently, the development of individualized approaches to service delivery, commonly called wraparound. ${ }^{6}$

Wraparound programs were developed in response to the absence of individualized services for children with SED $^{7}$ and have been viewed as pivotal to the delivery of services to children with challenging social and family needs and requiring services from a variety of agencies such as child welfare, mental health, special education, juvenile justice, and other service delivery agencies. ${ }^{8}$ In this approach, families are involved in a needs-driven process with formal (teachers, therapists) and informal (grandparents, neighbors) supports for developing an individualized plan of care that emphasizes child and family strengths across multiple life domains. Over time, ten essential elements of the wraparound approach have been identified by a noted group of researchers on wraparound and are listed in Table 1 . Based on the results of a 1998 survey, it has been estimated that approximately 200,000 youth and their families are receiving services through a wraparound approach. ${ }^{9}$

Numerous research and evaluation efforts have investigated the outcomes of wraparound services and their effect on the psychological and behavioral functioning of children and families. Improvements in overall functioning for youth have been reported, ${ }^{10,11}$ along with positive system outcomes such as reductions in the need for residential placements ${ }^{12}$ and decreased restiveness in living environment. ${ }^{13-15}$ However, equivocal results have been found with studies investigating improvement in school functioning ${ }^{12,13}$ and family functioning. ${ }^{11}$ While these studies provide a preliminary research base on wraparound, they suffer from a lack of controlled studies comparing wraparound with other interventions. ${ }^{9,16}$ However, before controlled studies that attribute outcomes to intervention can be conducted, reliable methods of monitoring and measuring the treatment fidelity of the wraparound process need to be developed. ${ }^{16}$

Table 1. Ten essential elements of the wraparound approach ${ }^{6}$

1. Wraparound services and supports must be based in the community.

2. Services and supports must be individualized, strength-based, and meet the needs of children and families across multiple life domains.

3. The process must be culturally competent and built on the unique values, strengths, and social and racial make-up of the families.

4. Families must be treated as full and active partners in every level of the wraparound process.

5. The wraparound approach must be a team-driven process involving the family, child, natural supports, and community service agencies working together to develop, implement, and evaluate the individualized plan of care.

6. Wraparound agencies implementing the services must have access to flexible, noncategorized funding.

7. Wraparound plans must include a balance of formal and informal supports.

8. Communities agencies and teams must provide services on an unconditional basis.

9. A service/support plan should be developed and implemented based on an interagency basis.

10. For each goal established, outcomes must be determined and measured for the child and family at every level of service. 
The study of treatment fidelity, a relatively new concept in the social services, has attracted a substantial amount of attention in service delivery and outcome research. ${ }^{17-19}$ Treatment fidelity refers to the concordance between implementation of the intervention and the intended theoretical and procedural design of the model ${ }^{17,18}$ and is an essential element in outcome research. ${ }^{20}$ With respect to research on children's mental health services, a crucial step in demonstrating the effectiveness of an intervention is to ensure that it has been adequately described and implemented..$^{21}$ Despite the need for methods of measuring wraparound fidelity, no widely accepted methodology exists ${ }^{6,16}$ because of the complexity and flexibility of the wraparound process..$^{21,22}$

Currently, two methods have been used to assess the fidelity of wraparound: surveys and observation approaches. Bruns et al. ${ }^{23}$ are currently validating the Wraparound Fidelity Index (WFI), a survey of parent, youth, and care providers who report on the presence of the key elements of wraparound. Malysiak-Bertram ${ }^{24}$ also assessed fidelity to the wraparound approach by using a survey methodology. After surveying 89 practitioners and 96 participants in the wraparound process, they concluded that while the values of the wraparound philosophy were well articulated, many elements of the approach were not being implemented as intended. More specifically, extended family and informal supports were not engaged in teams, service plans were typically limited and focused exclusively upon the environment in which they were developed (i.e., service plans developed in schools focused primarily on the child at school), strengths were rarely identified in meetings, and the manner in which service plans were reviewed and revised did not reinforce collaborative efforts with the families.

Another method for examining the fidelity of wraparound services is to observe the planning process during family planning meetings. Singh et al. ${ }^{25}$ reported on the development of the Family Assessment and Planning Team Observation Form (FAPT). The FAPT is a 42-item instrument used for measuring the treatment planning process in Virginia's system of care for children with SED and was designed to assess professional courtesy extended toward family members during team planning meetings. The authors reported that the FAPT achieved a satisfactory level of interrater reliability. Epstein et al. ${ }^{26}$ developed another observation form that was adapted from the FAPT. The 34-item Wraparound Observation Form (WOF) evaluated the delivery of wraparound services in a child welfare agency located in an urban midwestern city. Over the course of 10 family planning meetings, the WOF demonstrated adequate overall reliability (95\% interobserver agreement) and item-by-item agreement (70\%-100\%). ${ }^{26}$

Clearly, the wraparound approach has become a frequent option in supplying behavioral health care to children with SED and their families. Two major challenges, however, are apparent. The research findings on outcomes are equivocal and a systematic assessment of implementation is in its early stages. For outcomes to improve, supervisors need to understand what elements of the process are being implemented by practitioners in their agencies, direct care staff need to have a clear understanding of what they expect to achieve, and families need to develop an appreciation for the role of fidelity in the interventions provided to their children. However, before conclusive outcome research studies can be conducted, mechanisms for evaluating the fidelity of wraparound implementation need to be developed in a psychometrically sound manner.

In order to address the issue of fidelity of the wraparound process, the original WOF was modified to reflect the delivery of wraparound services to children and youth in a system of care. A committee of family members, care coordinators (i.e., wraparound workers), and administrators was asked to identify key elements of wraparound family planning meetings. Based on the input, the 48-item Wraparound Observation Form-Second Version (WOF-2) was finalized, and a new user manual for the WOF-2 was written. The purpose of this study was to examine the psychometric characteristics of the WOF-2 (i.e., interobserver agreement) and to evaluate the fidelity of the wraparound process during family planning meetings within a system of care for youth with SED and their families. 


\section{Method}

\section{Setting and participants}

Data were collected from families who participated in an evaluation designed to examine the impact of a system of care for children with SED and their families in Lancaster County, Nebraska. Lancaster County includes the Lincoln metro area and surrounding communities with a population of approximately 275,000 . The community was able to provide these services from a grant awarded by the Center for Mental Health Services (CMHS).

Team meeting observations $(N=112)$ were conducted with 63 families who participated in an evaluation designed to examine the utilization and outcomes from the system of care. All of the families in the study were enrolled in the local system of care, known as Families, First, and Foremost (F3), and were receiving services for a child who had SED based on CMHS criteria. Participation in the evaluation and observation was optional for families.

\section{Instrument}

The instrument used was the WOF-2, an adaptation of the WOF. ${ }^{26}$ The original 34-item WOF was collaboratively developed by evaluation team members and administrators to assess the implementation of the wraparound process during family planning meetings. First, the evaluation team members reviewed the literature on the wraparound process and identified the key features of wraparound. Second, they identified and modified the FAPT items to reflect the key features of the wraparound process. Third, the adapted form was given to agency administrators to evaluate for appropriateness of content, clarity, and readability. Fourth, the form was modified in accordance with the feedback from the administrators. Fifth, the form was piloted at two family planning meetings. Sixth, based on the feedback from the two pilot observations, evaluation team members made additional changes to the WOF. Finally, a user manual, which included operational definitions for each item and instructions for completing the form, was written. Over the course of ten family planning meetings, the WOF demonstrated adequate overall reliability (95\% interobserver agreement) and item-byitem agreement $(70 \%-100 \%){ }^{26}$

The 48-item WOF-2 elicits information on eight key characteristics of the wraparound process (see Table 2 for the key characteristics and items for each). The eight characteristics and 48 items were based on the essential elements of wraparound and from the input of consumers and family members. All 48 items are close-ended and require the observer to select one of the following three responses: Yes, No, or Non-Applicable. In addition to the 48 items, the WOF-2 identifies the participants at the meeting and their relationship to the child, life domains discussed in the plan of care, the location of the meeting, and length of time the team-planning meeting occurs.

\section{Procedure}

Six graduate students served as data collectors/observers. Before data collection began, the observers were trained on the use of the WOF-2 through didactic sessions with the research director, reading the WOF-2 manual, and observing wraparound meetings to familiarize themselves with the wraparound meeting process. Finally, each observer in training completed the WOF-2 at a minimum of three meetings along with an already trained observer to demonstrate competence. After the meeting, the forms completed by the two observers were assessed on an item-by-item basis. All item disagreements between the trainee and the observer were discussed and clarified after each meeting.

Prior to each meeting that was rated on the WOF-2, the observer presented the parent and the care coordinator with an observer confidentiality statement to verify family permission 
Table 2. Key dimensions, items, and results of observations on meetings $(N=112)$

Characteristic and variable

Community-based services

1. Information about resources interventions in the area is offered to the team.

2. Plan of care includes at least one public and/or private $109(97)$ community service/resource.

3. Plan of care includes at least one informal resource.

4. When residential placement is discussed, team chooses community placements for child(ren) rather than out-of-community placements, whenever possible.

5. Individuals (nonprofessionals) important to the family are present at the meeting. Individualized services

6. If an initial plan of care meeting, the parent is asked what treatments or interventions he/she felt worked/didn't work prior to F3.

7. Care coordinator advocates for services and resources for the family (e.g., identifies and argues for necessary services).

8. All services needed by family are included in plan (i.e., no needed services were not offered).

9. Barriers to service or resource/intervention are identified and solutions discussed.

10. The steps needed to implement the plan of care are clearly specified by the team.

11. Strengths of family members are identified and discussed at the meeting.

12. Plan of care that includes life domain(s) goals, objectives, and resources/interventions is discussed (or written).

13. Plan of care goals, objectives, or interventions are based on family/child strengths.

14. Safety plan/crisis plan developed/reviewed.

\section{Family-driven process}

15. Convenient arrangements for family's presence at meeting are made (e.g., location, time, transportation, and day care arrangements).

16. The parent/child is seated or invited to sit where he/she can be included in the discussion.

17. Family members are attended to in a courteous fashion at all times.

18. The family's perspective is presented to professionals from other agencies.

19. The family is asked what problems they would like to work on.

20. The parent is asked about the types of services or resources/interventions he/she would prefer for his/her family.

21. Family members are involved in designing the plan of care.

Yes (\%) No (\%) NA

$3(3)$

1

$91(81) \quad 21(19)$

$12(75)$

96

$37(33) \quad 75(67)$

$13(68)$

$6(32)$

93

110 (99)

1 (1)

1

$111(99)$

$1(1)$

$94(98)$

16

$106(95)$

1

$100(89)$

$12(11)$

111 (99)

110 (99)

1

$33(83)$

7 (17)

$112(100)$

110 (100)

2

111 (100)

1

92 (97)

3 (3)

17

106 (95)

5 (5)

1

106 (100)

...

6

$111(100)$
1

(continued) 
Table 2. (Continued)

\begin{tabular}{lccc}
\hline Characteristic and variable & Yes (\%) & No (\%) & NA \\
$\begin{array}{l}\text { 22. In the plan of care, the family and team members are } \\
\begin{array}{l}\text { assigned tasks and responsibilities that promote the } \\
\text { family's independence (e.g., accessing resources on own, }\end{array}\end{array}$ & $6(5)$ & 2 \\
$\begin{array}{l}\text { budgeting, and maintaining housing). } \\
\text { 23. The team plans to keep the family intact or to reunite } \\
\text { the family. }\end{array}$ & $104(95)$ & $5(5)$ & 3 \\
24. Family members voice agreement/disagreement & $111(100)$ & $\ldots$
\end{tabular}
with plan of care.

\section{Interagency/collaboration}

25. Professionals from other agencies who care about or provide resources/interventions to the family are present at the meeting.

26. Staff from other facilities or agencies (if present) have an opportunity to provide input.

27. Informal supports (if present) have an opportunity $37(100)$ to provide input.

28. Problems that can develop in an interagency team (e.g., turf problems, and challenges to authority) are not evident or are resolved.

29. Professionals from other agencies describe support resources/interventions available in the community.

30. Statement(s) made by a staff member or an informal support indicate that contact/communication with another team member occurred between meetings.

31. Availability of alternative funding sources is discussed $49(78)$

before flexible funds are committed.

\section{Unconditional care}

32. Termination of F3 services is discussed because of the multiplicity or severity of the child's/family's behaviors/problems.

33. Termination of other services (non-F3) are terminate because of the multiplicity or severity of the child's/family's behavioral problems.

34. For severe behavior challenges (e.g., gangs and drugs), 26 (90) discussion focuses on safety plans/crisis plans (e.g., services and staff to be provided) rather than termination.

\section{Measurable outcomes}

35. The plan of care goals are discussed in objective, measurable terms.

36. The criteria for ending involvement wraparound is $15(20)$ $104(93)$ discussed.

\section{Management of team meetings}

38. Key participants are invited to the meeting (i.e., family 109 (97) members, CPS worker, teacher, therapist, and others | significant to the family). 
Table 2. (Continued)

\begin{tabular}{|c|c|c|c|}
\hline Characteristic and variable & Yes $(\%)$ & No $(\%)$ & NA \\
\hline $\begin{array}{l}\text { 39. Current information about the family's status (e.g., } \\
\text { social history and behavioral and emotional status) is } \\
\text { gathered prior to the meeting and shared at meeting } \\
\text { (or beforehand). }\end{array}$ & $111(99)$ & $1(1)$ & $\ldots$ \\
\hline $\begin{array}{l}\text { 40. All meeting participants introduce themselves (if } \\
\text { applicable) or are introduced. }\end{array}$ & $72(88)$ & $10(12)$ & 30 \\
\hline $\begin{array}{l}\text { 41. The family is informed that they may be observed } \\
\text { during the meeting. }\end{array}$ & $110(98)$ & $2(2)$ & $\ldots$ \\
\hline 42. Plan of care is agreed on by all present at the meeting. & $111(100)$ & $\ldots$ & 1 \\
\hline \multicolumn{4}{|l|}{ Care coordinator } \\
\hline $\begin{array}{l}\text { 43. Care coordinator makes the agenda of meeting clear to } \\
\text { participants. }\end{array}$ & $77(72)$ & $31(28)$ & 4 \\
\hline $\begin{array}{l}\text { 44. Care coordinator reviews goals, objectives, } \\
\text { interventions, and/or progress of plan of care. }\end{array}$ & $102(96)$ & $4(4)$ & 6 \\
\hline $\begin{array}{l}\text { 45. Care coordinator directs (or redirects) team to discuss } \\
\text { family/child strengths. }\end{array}$ & $97(87)$ & $15(13)$ & $\ldots$ \\
\hline $\begin{array}{l}\text { 46. Care coordinator directs (or redirects) team to } \\
\text { revise/update plan of care. }\end{array}$ & $107(96)$ & $4(4)$ & 1 \\
\hline $\begin{array}{l}\text { 47. Care coordinator summarizes content of the meeting } \\
\text { at the conclusion of the meeting. }\end{array}$ & $75(67)$ & $37(33)$ & $\ldots$ \\
\hline 48. Care coordinator sets next meeting date/time. & 105 (94) & $6(6)$ & 1 \\
\hline
\end{tabular}

Percentages have been rounded.

for the observation and maintain the confidentiality of the family and participants. During the meeting, the observer marked Yes, No, or NA (not applicable) to each item and recorded the location of the meeting, the type of participants and their role during the meeting, and the length of the meeting on the WOF-2. At the conclusion of the meeting any questions that needed further explanation (e.g., convenience of the arrangements) were asked of the family or care coordinator. Reliability of the WOF-2 was assessed on twenty (18\%) of the family planning team meetings where two observers independently completed the WOF-2. Percent agreement and a kappa statistic were used to determine interrater reliability. The kappa statistic provides an estimate of agreement between observers corrected for chance and if agreement surpasses the expected level of chance, $\kappa$ approaches a maximum of $1.00 .{ }^{27}$

\section{Results}

\section{Reliability}

The average percent interobserver agreement across the six raters was $95.8 \%$ with a range of $75 \%$ to $100 \%$. An agreement of $100 \%$ was obtained on 29 items, and only one item fell below the $80 \%$ agreement level, Additionally, an average Kappa statistic of 0.88 with a range of 0.31 to 1.0 was obtained across the same observations. Forty-six of the 48 items exceeded the 0.61 level, which is considered to demonstrate substantial strength of agreement between raters according to the benchmarks described by Landis and Koch. ${ }^{28}$ 


\section{Meeting Location, Participants, and Focus}

The meetings occurred at the system of care office (44\%), the family's home (22\%), school $(22 \%)$, or other location $(12 \%)$. The mean number of participants at each meeting was 5.4 individuals (range $=2-10)$. One or both parents were present at almost all meetings $(89 \%)$. The most frequent professional participant was a therapist (38\%) and the most frequent informal support was a family friend (15\%) (i.e., neighbor and boyfriend/girlfriend). Other individuals present at many of these meetings included the child (55\%), mentor (25\%), siblings (23\%), Health and Human Services representative (21\%), and family (social) worker (21\%). The most frequently discussed life domains included education (86\%) and family (83\%). The least discussed life domains were cultural $(10 \%)$ and substance abuse $(15 \%)$.

\section{Observations}

A summary of the observations' raw scores, with the percent occurrence of "Yes" or "No" when applicable, is presented in Table 2. On average, for the five items included in the key dimension of community-based services, the desired behavior occurred $77 \%$ of the time, while for individualized services ( $n=9$ items), the desired behaviors occurred $92 \%$ of the time. For the 10 items in the key dimension of family-driven meetings, the desired behaviors occurred $98 \%$ of the time, while for interagency collaboration $(n=7$ items), the desired behaviors occurred $93 \%$ of the time and for unconditional care $(n=3$ items), the desired behaviors occurred $96 \%$ of the time. For the three items in the dimension of measurable outcomes, the desired behaviors occurred $69 \%$ of the time; for managing team meetings ( $n=5$ items), the desired behaviors occurred $90 \%$ of the time; and for the role of care coordinator ( $n=6$ items), the desired behaviors occurred $85 \%$ of the time.

An indication of adherence to the wraparound approach occurs when an item is scored as "Yes" for 46 items and "No" for 2 items (items \#32 and \#33). Adherence occurred over 90\% of the time for 35 of the 48 items, indicating the care coordinators were implementing the wraparound approach as intended.

\section{Discussion}

The results from the 112 observations using the WOF-2 demonstrated that for the most part, the care coordinators implemented the wraparound approach as it was intended. Further, the findings indicate a number of strengths and weaknesses in the adherence of the care coordinators to a wraparound approach. On the basis of the observations, families were consistently provided with information regarding resources or interventions within the immediate community. Care coordinators and team members also appeared to have a clear understanding of the strengths and resources provided within the neighborhood community and how to access community resources. Individualization of services was demonstrated through the frequent use of strength-based assessments, and frequent discussion of specific child and family strengths. On the basis of the observations, care coordinators for the most part treated the family as active partners. Plans were designed to keep families intact and in all of the meetings families were given opportunities to voice their agreement or disagreement with the plan of care. Furthermore, family and team members were often assigned tasks to promote the family's independence. Interagency collaboration was evident in the family planning meetings in that professionals from other agencies attended $81 \%$ of the meetings and, when present, described resources and interventions available in the neighborhood community. Goals were discussed in objective, measurable terms and an objective approach to verifying child and parent outcomes was consistently adhered too. Finally, there was ample evidence of effective team management and professionalism on the part of the care coordinators. 
Despite these positive observations, there were some items that indicate that the care coordinators were not adhering to the wraparound approach. Informal supports were present at only $33 \%$ of the meetings and extended family supports were present at only $9 \%$ of the meetings. The participation of informal supports and extended family members is an important part of the wraparound process because these individuals can serve as social supports for the family that can exist beyond public funding. The lack of participation or inclusion of informal supports at the team meetings may be due to a number of reasons. First, many of these team meetings were held during workday hours, which may make it difficult for family supports to attend. Second, many of the families receiving wraparound services were dealing with very personal, family issues that they may not want to share with individuals from outside the immediate family. Regardless, each of these reasons can be addressed through better planning and communication in order to increase the attendance of informal supports and extended family members at these meetings.

Further instances of lack of adherence to the wraparound process occurred in two other areas. First, discussions related to the criteria for ending the family's participation in wraparound occurred in only $20 \%$ of the meetings. While services and supports in a wraparound process are to be unconditional, families should have a set of goals and objectives for achieving success and permanence in the home and community independent of wraparound care coordination. Finally, as measured by the WOF-2, the area of unconditional care could not be rated in this sample of families as three-fourth of the meetings resulted in a rating of "nonapplicable" for this dimension. The high number of "non-applicable" ratings demonstrates that a large number of families were not presenting significant behavioral problems at the time of the observations.

\section{Limitations}

While the positive results of this study are encouraging, some limitations must be recognized. First, the scale does not measure cultural competence, a key element of wraparound. Several items to assess cultural competence were included in the initial WOF, but because of the difficulty in reliably observing these behaviors during family planning meetings, they were deleted from the scale. Second, while the WOF-2 measures the occurrence, or nonoccurrence, of specific behaviors, it does not measure how well they were implemented. For instance, a strength may be discussed in a rudimentary or nonfunctional manner, but still be identified as occurring during a planning meeting. Future investigators may wish to study this limitation by integrating a quality or competence dimension to the observation system. Third, observational measures are time and resource intensive in terms of training observers, assessing reliability, and conducting the actual observations. Future research on the development of the WOF-2 should continue to develop ways of reducing the number of items, determining the optimum number of observations needed to assess fidelity, and simplifying observer training and data collection procedures. Finally, the purpose of this study was to examine the interobserver agreement of the WOF-2 and to provide a descriptive picture of how wraparound is being implemented in communitybased settings. Future research is needed to determine how fidelity to the wraparound process, as measured by the WOF-2, relates to child and family outcomes.

\section{Implications for Behavioral Health Services}

Given the significant number of youth being served in wraparound programs nationwide and the variety of programs being implemented, the benefits of the WOF-2 and this research should not be ignored. First and foremost, the WOF-2 is a reliable instrument to monitor the implementation of wraparound services and determine how well staff adheres to the guid- 
ing principles of a wraparound approach. From an individual professional's perspective, data from the WOF-2 provide information on the behaviors that are being implemented as intended and should be reinforced, and which behaviors are not in line with the principles and require self-correction or further training. From an agency administrators perspective, the WOF-2 can be used for supervision purposes to identify the strengths and weaknesses of individual staff and the staff as a group. These data can be useful in designing and evaluating training efforts. From a system of care perspective, the WOF-2 provides an overall measure of how well staff are adhering to wraparound principles. These data may be useful in planning for system-wide training initiatives.

Several other important implications emerge from this study. The involvement of extended family members and other informal supports is critical to the wraparound approach. This study is a further indication of how challenging it is to achieve this principle and is similar to the findings of other researchers. ${ }^{24}$ To ensure the successful implementation of wraparound, providers must engage in extensive outreach activities to ensure the involvement of family members and informal supports. Finally, this study provides an example of the benefits that occur when community members, including families, behavioral health care providers, and researchers collaborate to assess the fidelity of community-based services. In addition, such collaborations help to convey the importance of fidelity of implementation to community members, families, and behavioral health care providers.

\section{Acknowledgments}

Preparation of this manuscript was supported in part by a grant from the U.S. Department of Education (H325D990035). Opinions expressed do not necessarily reflect the position of the U.S. Department of Education, and no endorsement should be inferred. The authors acknowledge the important role of Stephanie Nelson, Meredith Dickey, Megan Farney, Mandie Wharton, and Angela Gebhardt, who served the observers. Without their assistance this study could not have been conducted.

\section{References}

1. U.S. Department of Health and Human Services. Mental Health: A Report of the Surgeon General. Washington, DC: U.S. Dept of Health and Human Services; 1999.

2. Ringel JS, Strum R. National estimates of mental health utilization and expenditures for children in 1998. Journal of Behavioral Health Services and Research. 2001; 28:319-332.

3. Kutash K, Duchnowski AJ. Create comprehensive and collaborative systems. Journal of Emotional and Behavioral Disorders. 1997; 5:66- 75.

4. Stroul BA, ed. Children's Mental Health: Creating Systems of Care in a Changing Society. Baltimore, Md: Paul H. Brookes; 1996.

5. Burns B J, Hoagwood K, Mrazek PJ. Effective treatment for mental disorders in children and adolescents. Clinical Child and Family Psychology Review. 1999; 2:199-254.

6. Burns BJ, Goldman SW, eds. Promising Practices in Wraparound for Children with Serious Emotional Disturbance and Their Families. Washington, DC: Center for Effective Collaboration and Practice, American Institutes for Research; 1999. Systems of Care: Promising Practices in Children's Mental Health; 1998 Series, vol. IV.

7. Stroul BA, Friedman RM. A System of Care for Severely Emotionally Disturbed Children and Youth. Washington, DC: Child and Adolescent Service System Program (CASSP); 1986.

8. Clark HB, Clark RT. Research on the wraparound process and individualized services for children with multi-system needs. Journal of Child and Family Studies. 1996; 5:1-6. 
9. Burchard JD, Bruns, EJ, Burchard SN. The wraparound approach. In: Bums B, Hoagwood K, eds. Community-Based Interventions for Children and Families. Oxford: Oxford University Press; 2002: 69-90.

10. Bruns EJ, Burchard JD, Yoe JT. Evaluating the Vermont system of care: Outcomes associated with community-based wraparound services. Journal of Child and Family Studies. 1995; 4:321-339.

11. Eber L, Osuch R. Bringing the wraparound approach to school: a model for inclusion. In: Liberton C, Newman C, Kutash K, et al, eds. The 7th Annual Research Conference Proceedings. A System of Care for Children's Mental Health: Expanding the Research Base. Tampa, Fla.: Research \& Training Center for Children's Mental Health; 1995: 143-152.

12. Clarke RT, Schafer M, Burchard JD, et al. Wrapping community-based mental health services around children with a severe behavioral disorder: an evaluation of project wraparound. Journal of Child and Family Studies. 1992; 1:241-261.

13. Eber L, Osuch R, Reddit C. School-based applications of the wraparound process: Early results on service provision and student outcomes. Journal of Child and Family Studies. 1996; 5:83-89.

14. Rotto K, Sokol P, Matthew B, et al. Research for dummies: A practitioner's view of outcomes. Paper presented at the 11th Annual Research Conference. A System of Care for Children's Mental Health: Expanding the Research Base; 1998; Tampa, Fla.

15. Yoe JT, Santarcangelo S, Atkins M, et al. Wraparound care in Vermont: Program development, implementation, and evaluation of a statewide system of individualized services. Journal of Child and Family Studies. 1996; 5:23-39.

16. Rosenblatt A. Bows and ribbons, tape and twine: Wrapping the wraparound process for children with multi-system needs. Journal of Child and Family Studies. 1998; 5:101-116.

17. Hogue A, Liddle HA, Rowe C. Treatment adherence process research in family therapy: A rationale and some practical guidelines. Psychotherapy. 1996; 33:332-345.

18. Moncher FJ, Prinz RJ. Treatment fidelity in outcome studies. Clinical Psychology Review. 1991; 11:247-266.

19. Schoenwald SK, Henggeler SW, Brondino MJ, et al. Multisystemic therapy: Monitoring treatment fidelity. Family Process. 2000; 39:83-103.

20. Bickman L. The most dangerous and difficult question in mental health services research. Mental Health Services Research. 2000; 2:71-72.

21. Lourie IS, Stroul BA, Friedman RM. Community-based systems of care: From advocacy to outcomes. In: Epstein MH, Kutash K, Duchnowski A, eds. Outcomes for Children \& Youth with Behavioral and Emotional Disorders and Their Families. Austin, Tex: Pro-Ed; 1998: 3-20.

22. Burchard JD, Bruns EJ. The role of case study in the evaluation of individualized services. In: Epstein MH, Kutash K, Duchnowski A, eds. Outcomes for Children \& Youth with Behavioral and Emotional Disorders and Their Families. Austin, Tex: Pro-Ed; 1998: 363-384.

23. Bruns EJ, Burchard JD, Ermold JM. The Wraparound Fidelity Index: results from an initial pilot test. In: Newman C, Liberton CJ, Kutash K, et al., eds. The 13th Annual Research Conference Proceedings. A System of Care for Children's Mental Health: Expanding the Research Base. Tampa, Fla.: Research \& Training Center for Children's Mental Health; 2001: 339-342.

24. Malysiak-Bertram R, Bertram-Malysiak B, Duchnowski AJ. What maintains fidelity in a wraparound approach? Why is this important to families and providers? In: Liberton CJ, Newman C, Kutash K, et al, eds. The 12th Annual Research Conference Proceedings. A System of Care for Children's Mental Health: Expanding the Research Base. Tampa, Fla.: Research \& Training Center for Children's Mental Health; 1999: 197-202.

25. Singh NN, Curtis WJ, Wechsler HA, et al. Family friendliness of community-based services for children and adolescents with emotional and behavioral disorders and their families: an observational study. Journal of Emotional and Behavioral Disorders. 1997; 5:82-92,

26. Epstein MH, Jayanthi M, McKelvey J, et al. Reliability of the observation form: an instrument to measure the wraparound process. Journal of Child and Family Studies. 1998; 7:161-170.

27. Kazdin AE. Single-Case Research Designs. New York, NY: Oxford University Press; 1982.

28. Landis JR, Koch GG. The measurement of observer agreement for categorical data. Biometrics. 1977; 33:159-174. 